\title{
Criticism as a Creative Act
}

\section{Dean Wilcox ${ }^{1}$}

\author{
Reading texts is a matter of reading them in the light of \\ other texts, people, obsessions, bits of information, \\ or what have you, and then seeing what happens.
}

\section{—Richard Rorty, "The Pragmatist's Progress" in Interpretation and Overinterpretation}

In his essay "The Interpreter: A Self-Analysis" literary critic Geoffrey Hartman writes: "I have a superiority complex vis-à-vis other critics, and an inferiority complex vis-à-vis art."2 While I would not go so far as to assert his first statement, I often wonder if the second observation applies to my work in theatre criticism. It is an odd position, that of the critic, to reflect upon and write about the practical endeavors of others. The act of interpreting and analyzing that which was created without one's help is a tenuous action at best. And yet, writing critically about one's own work seems somewhat redundant. While I am reluctant to analyze my own theatre work, I revel in tearing apart and reassembling the work of others. Perhaps it is because in creating a piece of theatre critical energies are tied up in production, whereas with criticism practical energies are tied up in observation. I wonder if this point is the root of the superiority vs. inferiority that Hartman mentions or the origin of the tension between the practice of theatre and the criticism of theatre.

After spending long hours in a darkened space working to create something unique, something new, something practical, it is easy to dismiss the work of someone that merely writes about this action. It is easy to privilege the "doing" over the "talking about" since theory and criticism can be described as abstract or divorced from the "reality" of practical work. As opposed to an artistic activity that attempts to imbue something with meaning, criticism can be seen as an interpretation, an examination, or worse, the long-since debunked decoding of hidden meaning. Samuel Beckett's statements about James Joyce's writing clearly articulates this position: Beckett wrote that in Joyce's writing "form is content,

\footnotetext{
Dean Wilcox is the assistant dean for the Undergraduate Academic Program at the University of North Carolina School of the Arts. In addition to being a lighting designer, he has published articles and reviews in Theatre Journal, Theatre Survey, Journal of Dramatic Theory and Criticism, Theatre Research International, and Modern Drama.
} 
content is form" and that the work "is not about something; it is that something itself." "What, then, is the point of criticism if the meaning, form, and structure of a work are contained within the work itself? Why bother to employ complex and often convoluted theoretical ideas such as semiotics, deconstruction, or phenomenology to discuss a performance if the performance is already something itself?

This rift between the "doing" and the "talking about" often manifests an animosity that many practitioners have toward theory. As Gerald Rabkin articulates in "The Play of Misreading: Text/Theatre/Deconstruction," "most pragmatic American and British theatre people ... would second Laurence Olivier's remark that 'Personally, I loathe all abstract discussions of the theatre."' But, as Rabkin continues, the terms "theatre" and "theory" "have the same root-theasthai: to look on, view, contemplate - and consciously or unconsciously, all theatre has its theoretical base. ${ }^{\prime 4}$ It is this understanding that is echoed by Herbert Blau when he states, "[T] "there is already theory." Even a choice as elementary as a color palette has semiotic and theoretical implications since it affects how an entire production is viewed. Despite the fact that practice is clearly animated theory, I find that, when dealing with young actors, designers, and directors, I must continually reiterate that any method or practice demonstrates theoretical ideas whether articulated or not.

Regardless of this arbitrary division, theory and practice tend to collapse into the general idea of theatre. Even if one element seems to exist without the other, time proves the conjunction of the two. Take someone like Antonin Artaud, for example, who did have a background in the "professional" theatre, but is far better remembered for his theoretical ideas. By producing theory that he was unable, according to his contemporaries, to successfully convert into practice, he inspired generations of practitioners. The opposite is true of artists like Erwin Piscator and Vsevolod Meyerhold, who were primarily content to focus on practice with the hope of addressing theory later, which generally never came to fruition. It was left to succeeding generations to theorize their practice.

Theatre history seems to hold a special place for those like Konstantin Stanislavski, Bertolt Brecht, and Richard Wagner who were able to merge theory and practice in their work. From our historical vantage point their productions may be abandoned to time, outlined by descriptive or photographic residue, but their theories, which boost our knowledge of their practical ideas, remain undiminished for future generations. It is the combination of these elements that has made their work appealing to both critics and practitioners.

As someone who moves between the worlds of theory and practice, I am a firm believer that any act of criticism is a creative act. While this is not a new argument, I propose to explore a fundamental similarity between these two activities. The same interpretive problems arise in transferring a text from the page to the stage that arise in transferring a performance from the stage to the page. As critics we 
make choices, focus attention, employ metaphors, and conduct the viewpoint of our readers in the same spirit as actors, designers, and directors. In writing about performance, we employ similar strategies of focus, rhythm, pace, juxtaposition, and iteration that dominate the historical and contemporary stage. We use theory in a practical sense to create a form of theatre as we reflect upon the work of others.

It is this notion of creative criticism that I see contained in the Richard Rorty quotation above. Here, he raises two specific issues on the process of "reading texts" that I will extend to "reading" performances. The first is the use of "light" as a way of exploring texts via other texts, people, and obsessions. This is, quite obviously, a well-worn philosophical metaphor that carries with it connotations of eradicating darkness through analytical illumination. Oedipus' blindness and insight, Plato's allegory of the cave, idea-generated light bulbs precariously dangled overhead are all useful images of enlightened consciousness, which tend to include the notion of truth, reality, and/or inspiration. The second point, which may take some time to address, has to do with the pragmatic notion of "seeing what happens."

I have an interest in light not merely as a symbolic tool but also as an artistic medium. I come to the world of theatre criticism from the world of lighting design. I say this not to brag or apologize, but to situate my critical aesthetics within the currency of usability that comes with practical theatre training. I was reared in an environment where one makes of things what one can, given the perpetual looming deadline of opening night. What initially attracted me to the field of lighting design was not that it can be used symbolically, but that it offered to someone like me, who was interested in design but had limited drawing skills, an intangible medium — one in which the designs are informed by thought, concept, language, and description. In this sense, lighting design is as dependent upon theoretical ideas as it is upon aesthetics.

Light is essentially energy, invisible and immaterial until it is animated by the material world. Objects within a field of vision both absorb and reflect light, and it is this symbiotic relationship that allows objects to become visible, light to become "material." Unlike light, which has the quality of dissemination, objects are finite; they have contours, limits, boundaries, and are used to define spatial relationships. Objects present specific information, like color, which is revealed, by light reflecting off a surface, thus creating the highlight and shadow that enable us to apprehend the visual world. While Parker and Smith argue in the classic Scene Design and Stage Lighting that "light reveals form," it can also be said that form reveals light.

This process is compounded by the fact that surrounding objects also absorb and reflect light that, in turn, falls upon other objects. This nearly invisible process of reflection upon reflection upon reflection animates the entire visual field. Shadow, which can best be defined as "an outgrowth of the object that cast it," "7 helps situate the object in space and in relation to other objects, including the viewer. Objects, then, are never seen in isolation, but always in contrast with the position of the 
viewer, other objects, their shadows, and their reflected light.

Training as a lighting designer, I quickly discovered that the process of manipulating the illumination within a performance is not as simple as turning on a light. Rather, it is a complex process of interaction between objects and energy grounded in the overall flow of a performance, which is often derived from an interpretation of an original text. Within the theatre we approach what Roland Barthes might call "multi-dimensional space" in which a variety of elements - a seemingly inexhaustible list of signifying elements including text, body, gesture, setting, properties, costume, lighting, and make-up, among others - "blend and clash" to create the performance. ${ }^{8}$ I was fascinated as a young designer by the fact that while light could not substantially alter objects on stage, it could, through the manipulation of color, angle, intensity, contrast, and movement, alter the appearance of objects on stage. ${ }^{9}$

I am not arguing that lighting design should be given a prominent position in the hierarchy of production elements; rather, my argument is a more theoretical one, namely that an immaterial element like light greatly affects how we perceive the objects and, thereby, texts placed in front of us. In dealing with the material world, one must keep in mind Rorty's first point that the act of reading - of a text, performance, object, gesture, or any other semiotic process-involves a triadic negotiation between "text," reader, and "light," or a particular analytical frame of mind. These are not separate pieces but, like light, objects, and viewer, cohere as a dynamic interaction of elements. Since objects, texts, and gestures are always viewed in contrast to other objects, texts, and gestures, the overall context, loosely defined as the immediate visual field or analytical approach, will always bear upon the act of interpretation and understanding. While Joyce's work, then, may be "that something itself," it is not so in isolation from other works, theories, ideas, or practices.

Joyce, like any artist, is a product of his time and any attempt to isolate his work from its context, or, say, a signifying element from the ebb and flow of a performance, is doomed to become Olivier's loathed abstraction. By way of pushing the light metaphor a bit further, I want to consider two very different ideas behind color theory as a way of structuring this discussion and underscoring the difference between theory as an abstraction and criticism as an act of creativity. Anyone who has ever seen a textbook image of the color spectrum is aware of Newton's color theory. Using a prism Newton "abstracted" white light into its constituent parts: red, orange, yellow, green, blue and violet. What Newton uncovered were the different frequencies of light perceptible to the human eye. The prism allowed him, as it were, to see the components that make up white light split apart. While it is hard to deny the importance of Newton's discovery, it is rare to find light in the "natural" world divided into such pure elements since any beam of light will inevitably interact with objects, shadows, and reflections. This is how theory and 
criticism can be viewed: as abstractions, separate from the flow of performance, a clinical examination divorced from practice.

Now, far be it from me to refute the work of Sir Isaac Newton. My point here is that his exploration of light, while valid, removed that light from any kind of practical or "natural" situation. There are, however, other models to explore. Working one hundred years after Newton, Goethe developed a completely different theory of color in light. Rather than isolate light in a laboratory, Goethe took his prisms outside and looked at clouds, trees, and reflective surfaces. What Goethe developed was a theory based on the interaction of light and objects in which the viewer was integral to the image. As James Gleick points out in his exploration of Chaos Theory,

Goethe refused to view color as a static quantity, to be measured in a spectrometer and pinned down like a butterfly to cardboard. $\mathrm{He}$ argued that color is a matter of perception. "With light poise and counterpoise, Nature oscillates within her prescribed limits," he wrote, "yet thus arise all the varieties and conditions of the phenomena which are presented to us in space and time."10

Newton was a scientist (for some, the scientist), whereas Goethe was a Romantic poet and philosopher. Newton interrupted a beam of light with a prism and observed what happened on the laboratory wall. Goethe looked through prisms, studied shadows, and examined the different qualities of light that existed in the world around him. Newton's scientific approach, in short, revealed a clinical understanding of color and light, whereas Goethe's rested on a philosophical or pragmatic understanding.

It is this notion of light described by Goethe as a dynamic interaction between elements that I see in relation to Rorty's shining of people, obsessions, and texts upon other texts. The light of these texts is not intended to be more truthful, especially for a pragmatist like Rorty, but merely to provide an illuminating energy for the current reading. It is here where interaction, contextualization, illumination, tension, and contradictions between elements are all possible outcomes. Like my understanding of light as a young designer, Rorty's light does not alter the substance of the text but can alter its appearance.

It was with a background in lighting design and a mindset focused on convergences, then, that I initially encountered the theoretical perspectives offered by semiotics, feminism, Marxism, deconstruction, and phenomenology. As my training began to focus less on practical matters and more on theoretical positions, I wondered how far this idea of convergences could be taken. I pondered where the limits of this interaction were when it came to literature, theory, history, and performance analysis. I became fascinated with the ideas and techniques developed 
by studying lighting design in a theoretical, as opposed to a practical, sense.

Despite Blau's argument that the shadow of theory exists in any act of theatre, my practical experience suggested that in most, but not all, situations theories were often best left outside the doors of the theatre. I recall once as a design student I was told, "[C]ritics write about what we do." Although I saw the gesture as one of commonality as well as separation, it underscored the rift between theory and practice that dominated the field of theatre studies at that time. Aside from evoking a kind of phenomenological chasm between thinking and doing, this statement seemed to suggest that somehow criticism, theory, or analysis were like light - intangible and immaterial — until they encountered something solid, like practical action.

As I began to think about this underlying connection between the two, I continued to return to the notion that without light objects remain invisible, and that without objects the materiality of light remains at the level of imperceptible energy. My hope with the discussion above was to establish a symbiotic relationship between light and object in which both are essentially invisible until combined. There is no hierarchy intended here; neither is more important than the other. Light and object are, in fact, interdependent, and while their relationships with each other make both of them visible to us, each relationship is merely a physical process and nothing more. Light shines upon objects and they reflect light and can be seen; this process, in turn, reveals color, shadow, gaps between objects, spatial context, and interactions between elements.

I have no intention (no matter how tempting) to argue that a performance remains "invisible" until the light of analysis shines upon it. I do believe, like Beckett, that a work of art is something, and that any discussion of that work is a form of translation from one medium to another. But I also subscribe to the idea that theory can reveal something about the form or structure of a performance that may not initially be apparent. My goal with this essay is to employ this distinction between the purely analytical and the pragmatic to discuss the process of performance criticism in relation to theory and practice. To be more specific, I want to explore my own process as a designer as it relates to the process of performance analysis.

Interpreting and analyzing that which was created without one's input is generally acknowledged as a peripheral or supplementary action at best. We are almost always outside the text, peering in, entering into this process, at least, once removed. Our tools are observation, description, theory, and analysis, none of which we can point to in the concrete manner that one can point to work on the stage and say, "This is solid, this is performance, this is something that I have done."

One of the appealing elements of theoretical positions is that they are fundamentally abstract ideas, as intangible as light, in need of a surface to be made visible. Theoretical positions, in short, need objects of inquiry, tangible, practical examples to animate analytical concerns. Theory, like light, shines upon "texts" 
to reveal meanings, form, gaps, contexts, and interactions between elements. Deconstruction, for example, is essentially a parasitic enterprise in which one needs something — a text, a philosophical premise, a work of art — to deconstruct. The analysis is not completely external but, like light, reveals what is already there, altering, perhaps, the initial appearance. As a theoretical perspective, deconstruction brings nothing to the object of analysis that isn't already contained within the target text. It is a form of intellectual jujitsu fully dependent upon its subject since the "obvious or univocal reading' always contains the 'deconstructive reading' as a parasite encrypted within itself as part of itself." 11 This is, like any theoretical approach or artistic activity, a process animated by the process itself.

Similar to the light of other texts mentioned by Rorty, Barbara Johnson points out that Jacques Derrida's deconstructive approach is conditioned by that fact that his writing "is always explicitly inscribed in the margins of some preexisting text" and that he is "first and foremost a reader who constantly reflects on and transforms the very nature of the act of reading." 12 If Derrida is first and foremost a reader, then he is presumably involved in an active process of interpretation, of struggle, of encountering and assaulting problems, of "doing." This is, I suppose, a comment best supported by the fact that many people have written about what he has done.

Years ago, after first being introduced to Derrida's work, I endeavored to use some of his ideas, as Rorty says, to see what happens. Although Derrida bristled at the notion of a singular definition of deconstruction and was even more averse to treating it as a methodology that could be applied to various texts and situations, I explored it as a particular way of reading. What I discovered was that Derrida's notion of the "hymen," which can be described as a "fragile membrane that functions as a barrier between one area and the next, existing in neither, but allowing both to exist concurrently" was extremely useful in discussing the performance style of Karen Finley. ${ }^{13}$ Her early work exemplified the notion of "in-between-ness" articulated by Derrida, and, by applying his idea (with all of the sexual innuendo in tow) to her work, I was able to see something I felt was fundamental in her performance technique.

This is not to say that swiping an idea from Derrida and applying it to Finley's work fundamentally changed the work, but it gave me a vocabulary and a focus to see something I had not initially seen. It revealed, like the interaction of light and object, an underlying form. Here, I had three separate pieces: Derrida's notion of the hymen, a recorded segment of Finley's Constant State of Desire (1986), and my own observations. It was the convergence of the three, however, that yielded the essay. While this did not fundamentally change Finley's performance, it did change how it appeared to me and, thereby, became a way of analyzing that performance and of providing a specific focus to subsequent readers.

Moving from design to criticism, I was able to see that the two share, not the light of truth, but a fundamental basis in asserting a choice of focus. Stage 
lighting, through the manipulation of the elements mentioned above, helps to establish location, time of day, mood, and atmosphere. More importantly, however, through highlight and shadow, lighting directs the eye, tells the audience what to look at, what elements to pay attention to. This is exactly what I attempted to do by utilizing a theoretical idea to explore a "text," to direct the eye by asking certain questions and reading in a specific manner. The argument here is that the arbitrary division between analysis and doing is not as solid as it appears. What links these two processes, the practical and the analytical, is that method of doing, a procedure that operates through such techniques as interaction, contextualization, tension, and contradiction to illuminate specific ideas. Or, to be less specific, it is a process of putting elements together and seeing what happens.

One of the things I enjoy about designing for the theatre is the trial-and-error process of technical rehearsals. While I was taught to have a fairly good idea of what the production should look like prior to entering the performance space, imagination can only go so far. The question "What happens if I do this?" presumes that hidden messages may be as shallow as a hasty decision made while any number of people wait to move on to the next section of the rehearsal. In an ideal situation, all facets of a production are thought out, understood, discussed, and executed with precision. Working in the theatre, though, has taught me that ideal situations are few and far between. It is the practical notion that despite the best efforts and intentions a performance always has an opening night and that decisions have to be made and executed.

For a critic who is outside this process to peer in and assume that all elements are designed to cohere toward a common purpose or meaning is, at best, a suspension of disbelief. The act of creating a performance is a great deal more complex than a work by a single author if for no other reason that there may be, despite all the lip service paid to collaboration and directorial authority, multiple agendas at work within any given moment. While it may be possible to derive $a$ meaning from performance, it will always be in contrast to a proliferation of intended and unintended meanings. One of my favorite examples of this is Piscator's use of large treadmills to create his production of The Good Soldier Schwejk (1928). Deafening in rehearsals, the motors were quieted as much as possible but still remained audible and quite humorous in performance. Though not necessarily the initial objective, Piscator had "accidentally discovered the potential for subversive humor inherent in the modern stage apparatus itself. In one stroke, not only was the arbitrariness of spatio-temporal construction made apparent as ideological but the mystical aura of the machine also evaporated." ${ }^{14}$

This is not to suggest that all practical choices are arbitrary since, like the process of performance analysis itself, they are inevitably judged against the production to assess how the choices work within the performative context. But anyone that has ever had a "happy accident" in the rehearsal process, where an 
unintended element is woven into the fabric of the final performance, understands that this process can include capricious or partially understood ideas. My favorite example of this is Eugenio Barba's discussion of his 1985 production of The Gospel According to Oxyrhincus in which he reexamined Antigone. In his essay "The Shadow of Antigone," Barba discusses the moment when the Grand Inquisitor Jehuda approached Antigone shortly after she covered her brother's severed head with her dress. Jehuda did not kill Antigone, but attacked her shadow with a dagger by scraping at its edges. He proceeded to "outline the shadow with the dagger and at the same time seem[ed] to be trying to efface it." 15

As Barba points out, "I worked for a long time to find all the details for this scene, without knowing why. I asked myself all the while: why am I working so much on this scene, why is this scene so essential for me?"16 It was only later when watching a television program about the bombing of Hiroshima that he fully understood the impact of this gesture. The blast from the bomb literally burned the image of people into buildings, steps, and sidewalks. Barba now understood the scraping of Antigone's shadow since "it is easy to kill bodies, very easy, but some bodies leave shadows, as if their lives were so loaded with energy that they remained imprinted on history." is always qualified by the performance as an object that pushes back, provides resistance, dictates whether the choice fits within the current context and whether it is fully understood or not.

The same is true for the process of performance analysis. While it's possible to anticipate that performative choices are designed to cohere by serving a common goal, a critic that simply lists or narrates these choices offers very little in the way of analysis. If there is too clean a fit between theory and practice, the work of the critic seems somewhat redundant. In this case, it's as if the production had already done the analytical work, and the job of the critic was to point out the obvious. If the purpose of analysis is to illuminate a performance in a specific way, then the use of performance material necessitates that examples not only animate but also push back on and raise questions about what is essential to a performance. These examples, in short, provide resistance to the theory. Like the process of testing choices in rehearsal, practical examples challenge the theory to see if it stands up to use. Roland Barthes articulates this idea when he likens the process of reading to hammering a nail into a piece of wood, which has "a different resistance according to the place you attack it." 18 This is as true of every lighting design I have ever created as it is of combining Derrida and Finley. Choosing a different color palette will create a radically different design as will choosing a different theory to discuss a performance.

This point underscores the fact that if a performance can be constructed in a multitude of ways then it can be analyzed in a multitude of ways. One can discuss the narrative, the plot structure, the visual structure, the contradictions between 
signifying systems, the intended or received messages, the performance style, or explore a single defining moment. Each of these avenues for analysis may provide different areas of resistance that suggest different theoretical approaches. Like choosing between a red color filter or a blue one, the choice to use phenomenology, deconstruction, feminism, or Aristotlean analysis will alter how the performance object is viewed. It is not that theory simply exposes a hidden meaning, but that the interaction of the performance object and the method of analysis actually creates a meaning.

The Newtonian approach looks to pin the object down, dissect it, and search for a clearer understanding of the whole through its parts; Goethe, on the other hand, understood that his own perception conditioned the reception of light and shadow in the natural world. While Newton may have uncovered a "truth" about the different frequencies of light, he did so by limiting his perception. Articulating the rift between the phenomenological and the analytical, Maurice Merleau-Ponty points out, "We never cease living in the world of perception, but we go beyond it in critical thought - almost to the point of forgetting the contribution of perception to our idea of truth." ${ }^{19}$ The point signaled by this juxtaposition between Newton and Goethe's methods is that $a$ meaning should never be confused with the meaning since analysis, like light, cannot change the object but only how it is viewed.

This statement, finally, brings me to Rorty's second point in the opening quotation: after reading texts in light of other texts, the next step is "seeing what happens." In my own writing process, I understand an essay I'm composing by writing it completely, as opposed to merely outlining it or thinking about it. The "doing" is central to my construction process. Each revision of an essay refines its message as certain elements are developed and others marginalized. This is the same trial-and-error process used in theatre practice. In creating a performance and constructing an analysis, ideas are tried out, interpretations are challenged, and components are rearranged, added, and cut, with the eventual shaping of the work into a finished product.

While I may interpret the role of theatre critic as having a responsibility to the work and the reader by providing background or historical material and placing the performance into a particular context, I am often more interested in what a performance can be used to do. Analysis is not limited to what meaning can be drawn from dissecting an object; it is about "seeing what happens," seeing what can be made out of a performance, what resistance it will provide, what questions it will raise, and how the process of reading this complex text will affect the act of reading itself. This is an action that should not be confused with imposing an idea on a production. Theory is a valuable tool that should be used to construct an argument, not defend one.

Employing, as I have in the past, a deconstructive strategy to explore the work of Karen Finley, Bill Viola, and Robert Wilson was often less about the 
work and more about the process of exploring the ideas they generated within a specific context. As a critic, I did not function as a decoder of the work, isolating performance elements as Newton fragmented light into smaller and smaller pieces. I approached these "texts" like Goethe by wandering around inside the material to see what could be seen and to see what happened when I looked through this particular prism or explored this particular theoretical idea. This type of activity is not about cracking or revealing a hidden code, or as Rorty cautions, assuming criticism is about "discovery rather than creation," ${ }^{20}$ but a creative act aligned with Barthes's notion of jouissance, or the pleasure of playing with, in, and through the text.

Traditionalists, of course, will argue that if a work is created with a specific intention then reading it in a different way is a misinterpretation or overinterpretation. Eco raises this point in assessing the role of the reader when he stresses the difference between interpretation and use. For Eco, "[T]o critically interpret a text means to read it in order to discover, along with our reactions to it, something about its nature." To use a text, however, "means to start from it in order to get something else, even accepting the risk of misinterpreting it from the semantic point of view." 21 In this sense, the act of creating a performance by interpreting an originary text is no different than creating an analysis by reading a performance. What qualifies this process is the pragmatist's skepticism of ever being able to discover anything specific within a text at all, let alone its "nature." As Rorty explains,

Having read Eco, or having read Derrida, will often give you something interesting to say about a text which you could otherwise not have said. But it brings you no closer to what is really going on in the text than having read Marx, Freud, Matthew Arnold or F.R. Leavis. Each of these supplementary readings simply gives you one more context into which you can place the text - one more grid you can place on top of it or one more paradigm to which to juxtapose it. ${ }^{22}$

This is not to suggest that performances should be viewed as fodder for what Eco calls "interpretive drift," ${ }^{23}$ but if a performance is a unified whole built from a wide array of parts, and possibly agendas, then the notion of intention may be as multifaceted as the text itself.

Recently, I have become fascinated with the subject of postdigital technology in the form of hypertext, essentially nonlinear linked text and images. The most visible example of what I am referring to is the internet, but, to take advantage of the Barthes references above, one might also suggest Barthes's $S / Z$, an early printed hypertext. This offers a useful metaphor to discuss the creative role of the critic. Like performance, it is a fluid medium that is never approached the same way twice but constantly built up from a collection of links and reader-oriented 
choices. The author's job, then, is to provide the raw material and the fundamental organization for the project, while the process of assembling, organizing, and "doing" is left up to the reader.

Since individual readings vary widely according to who is reading and what choices they make, the reading process continually feels like a scripting process in which one is an active participant. Certainly, most readings, as Johnson indicates with her discussion of Derrida, have the potential to be active and critically engaged, but this process, via hypertext - a medium that often allows the reader to add their own comments, links, and material — is greatly magnified. Absorbing the fragmenting strategies of the historical avant-garde, contemporary computer technology offers a widely flexible medium in which the boundaries of "object" and "light" are often blurred. The internet exists as both a performative and critical space in which readers can share their own personal pathway through this type of material, bringing in their own ideas, obsessions, and questions to bear upon creative work, thereby further blurring the line between theory and practice.

Charles L. Mee, perhaps best described as a postmodern historian/dramatist, has created a website that offers exactly this type of activity for his published texts. Known as "the (re)making project," this website offers readers free use of Mee's work as a resource for their own work. Mee, in fact, advocates that readers "pillage [his] plays as I have pillaged the structures and contents of the plays of Euripides and Brecht and stuff out of Soap Opera Digest and the evening news and the internet, and build your own, entirely new piece." ${ }^{24}$ This iterative gesture illustrates the creative process as one that both interprets and uses texts of all kinds to arrive at a final product that is, then, offered up for the same cannibalistic process. Mee's comments about pillaging could serve as sage advice for the process of performance analysis in which the critic weaves together multiple sources, including an original "text," the performance, theoretical models, and analytical methods filtered through personal observation to build an entirely new work. This new work, however, is not closed on meaning but is addressed as part of an ongoing process of recontextualization. Or, as Rorty points out, this new work is but one more grid one can place on top, which allows others to perpetually reexamine older works in a new theoretical light.

More recently, the term "postdramatic" has been adopted to define a genre that further blurs the notions of text, interpretation, theory, and practice. Writing about such artists as Robert Wilson, Heiner Müller, Sarah Kane, and The Wooster Group, Hans-Thies Lehmann explains that postdramatic theatre "most definitely does not mean a theatre that exists 'beyond' drama, without any relation to it. It should rather be understood as the unfolding and blossoming of a potential of disintegration, dismantling and deconstruction within drama itself." ${ }^{25}$ While works labeled postdramatic may offer commentary and criticism on specific texts or styles, as well as on the performance itself, they are not closed onto a specific meaning 
but resonate multiple meanings simultaneously.

One glance at the "script" for Müller's Explosion of a Memory or Kane's 4:48 Psychosis should convince anyone that something has changed since the days of traditional dramatic texts. These works exist as blocks of language devoid of character, space, description, and often narrative. Nevertheless, they were created as dramatic works designed to be interpreted on stage. Like Joyce's work, these pieces are, indeed, not about something but are that something itself; this something, however, is widely open to interpretation and augmentation depending upon which elements are magnified or added in performance. Working within the history of drama and outside the traditional notion of "text," postdramatic works collapse the categories of doer, maker, and spectator creating what Eco might refer to as an "open work." 26

Much has changed since I first encountered the supposed rift between theory and practice, and the idea of postdramatic theatre, embryonic at that time, offers an alternative to this split. Clearly, if folks like The Wooster Group can offer deconstructions of works by Chekhov and Gertrude Stein in which added media, gestures, dances, and images augment the initial text, then the only difference between theory and practice is the method of delivery. How different is their exploration of Stein's work from Derrida's of Artaud's? Do we privilege one as "a work of art" because it is presented on stage and the other as "philosophy" or "literary criticism" since it is presented in another form? If the artist's role is to use aesthetic properties to make something out of something else, and the critic's role is to use theoretical models to make something out of something else, then the dividing line between these activities is as permeable as the one dividing life from art. For those unable, or unwilling, to accept the role of explainer or decoder of the text, what remains is criticism as a creative act in which elements of performance and theory combine to create a new text, which, in turn, contributes to the chain of light observed by Rorty.

This is the space in which analysis takes place: between the performance and its interpretation, between the practice and the theory, between the object and the light. Each animates the other and, then, is reflected outward to further animate other texts. I am a firm believer that any act of criticism is a creative act. From my own perspective, my work as a lighting designer follows a very similar pattern to my work as a critic. I have found that the same interpretive problems arise in transferring a text from the page to the stage that arise in transferring a performance from the stage to the page. As a designer, I make choices, focus attention, draw on metaphors, and conduct the viewpoint of the audience in the same way that I do as a critic. In writing about performance, I employ similar strategies of focus, rhythm, pace, and juxtaposition that dominate the historical and contemporary stage. As I reflect upon the work of others, I, in a very real sense, create performances, objects placed into the world to shine upon and reflect off other objects. My goal 
in either medium is always to make something out of something else. I say this not to defend the actions of those who are thought to "write about what others do," but to underscore the commonality of process between theory and practice, between performance and analysis.

\section{Notes}

1. The author is indebted to members of the Performance Analysis Working Group for their feedback on an early draft of this essay presented at the IFTR conference in Washington, D.C. June 2005, and for the constant inspiration by members of UNCSA's "Make Group," Bob King, Joe Mills, and Betsy Towns.

2. Geoffrey Hartman, The Fate of Reading (Chicago: U of Chicago P, 1979) 3.

3. Samuel Beckett, Disjecta: Miscellaneous Writings and a Dramatic Fragment (New York: Grove, 1995) 27.

4. Gerald Rabkin, "The Play of Misreading: Text/Theatre/Deconstruction," Performing Arts Journal 7.1 (1983): 44-60. 1982) 1.

5. Herbert Blau, Take Up the Bodies: Theater at the Vanishing Point (Urbana: U of Illinois P,

6. W. Oren Parker and Harvey K. Smith, Scene Design and Stage Lighting, $4^{\text {th }}$ ed. (New York: Holt, Rinehart and Winston, 1979) 54.

7. Rudolf Arnheim, Art and Visual Perception: A Psychology of the Creative Eye (Berkeley: U of California P, 1954) 317.

8. Roland Barthes, Image - Music - Text (New York: Noonday, 1988) 146.

9. After exposure to theory and criticism, I would address this by discussing the process of defamiliarization or the collision of signifying systems and phenomenological essences. While this vocabulary did not necessarily make me more aware of this process it did provide a more specific way to articulate it.

10. James Gleick, Chaos: Making a New Science (New York: Penguin, 2008) 164.

11. J. Hillis Miller, "The Critic as Host," Deconstruction \& Criticism (New York: Continuum, 1979) 224.

12. Jacques Derrida, Dissemination, trans. Barbara Johnson (Chicago: U of Chicago P, 1981) x.

13. Dean Wilcox, "Karen Finley's Hymen," Theatre Research International 22.1 (Spring 1997): 31-37. While I am uncomfortable quoting something from one of my own essays, I am using this as an example of the convergence of theory and practice. Any attempt to speak about this process in an essay by someone else would seem far more presumptive. 2000) 41 .

14. Sarah Bryant-Bertail, Space and Time in Epic Theatre (Rochester, NY: Camden House,

15. Eugenio Barba, "The Shadow of Antigone," The Actor's Way, Erik Exe Christoffersen (New York: Routledge, 1993) 183.

16. 183 .

17. 184 .

18. Roland Barthes, The Pleasure of the Text (New York: Hill and Wang, 1975) 36.

19. Maurice Merleau-Ponty, The Primacy of Perception (Evanston, IL: Northwestern UP, 1964) 3.

20. Richard Rorty, Consequences of Pragmatism (Minneapolis: U of Minnesota P, 1982) 152.

21. Umberto Eco, The Limits of Interpretation (Bloomington: Indiana UP, 1990) 57.

22. Umberto Eco, with Richard Rorty, Jonathan Culler and Christine Brooke-Rose, Interpretation and Overinterpretation (Cambridge: Cambridge UP, 1992) 105.

23. 52 .

24. Charles L. Mee, the (re)making project $<\mathrm{http}$ //www.panix.com/userdirs/meejr/indexf.html $>$.

25. Hans-Thies Lehmann, Postdramatic Theatre (New York: Routledge, 2006) 44.

26. Umberto Eco, The Open Work, trans. Anna Cancogni (Cambridge: Harvard UP, 1989). 